\title{
BMJ Open Update on Noma: systematic review on classification, outcomes and follow-up of patients undergoing reconstructive surgery after Noma disease
}

Sophie Speiser (D) , ${ }^{1}$ Benjamin Langridge, ${ }^{1,2}$ Moira Melina Birkl, ${ }^{3}$ Harald Kubiena, ${ }^{4}$ Will Rodgers ${ }^{5}$

To cite: Speiser S, Langridge B, Birkl MM, et al. Update on Noma: systematic review on classification, outcomes and follow-up of patients undergoing reconstructive surgery after Noma disease. BMJ Open 2021;11:e046303. doi:10.1136/ bmjopen-2020-046303

- Prepublication history and additional online supplemental material for this paper are available online. To view these files, please visit the journal online (http://dx.doi.org/10. 1136/bmjopen-2020-046303).

Received 30 0ctober 2020 Accepted 14 July 2021

Check for updates

(C) Author(s) (or their employer(s)) 2021. Re-use permitted under CC BY-NC. No commercial re-use. See rights and permissions. Published by BMJ.

${ }^{1}$ Division of Surgery and Interventional Science, University College London, London, UK

${ }^{2}$ Department of Plastic Surgery, Royal Free London NHS Foundation Trust, London, UK ${ }^{3}$ Karl Landsteiner University of Health Sciences, Krems, Niederosterreich, Austria ${ }^{4}$ Dr.Kubiena, Private Office, Vienna, Austria

${ }^{5}$ Department of Dental and Maxillofacial Surgery, Great Ormond Street Hospital for Children NHS Foundation Trust, London, UK

Correspondence to

Dr Sophie Speiser;

sophie.speiser.19@ucl.ac.uk

\section{ABSTRACT}

Introduction Noma is a significant yet neglected disease which affects some of the least developed countries in the world. The long-term benefit and safety of Noma surgical reconstructive missions have recently been under scrutiny due to a perceived lack of measurable outcomes and appropriate follow-up. This study analyses and reports on classifications, outcome measurement tools and follow-up for reconstructive surgery after Noma disease.

Methods This systematic review was undertaken following Preferred Reporting Items for Systematic Reviews and Meta-analyses guidelines. The three medical databases Medline, EMBASE and Web of Sciences were searched, articles published between 1 January 1983 and 15 April 2020 were included. All primary evidence on reconstructive surgery following Noma disease, reporting data on outcome after surgery, follow-up time and complications were included. Extracted data were aggregated to generate overall and population corrected mean outcomes and complication rates.

Results Out of 1393 identified records, 31 studies including 1110 Noma patients were analysed. NOITULP and Montandon/WHO were the most commonly used classification systems. Mouth opening (MO) and complication rates were the two most often reported outcomes. Overall mean complication rate was $44 \%$, reported by 24 studies. Postoperative M0 was reported by eight publications, of which, five reported long-term outcomes (>12 months). Mean M0 improved by 20 $\mathrm{mm}$ when compared with mean population weighted preoperative M0 (7 mm). At long-term follow-up, M0 decreased to $20 \mathrm{~mm}$.

Conclusions Studies reporting on neglected diseases in developing countries often lack methodological rigour. Surgeons should be mindful during patient examination by using a classification system that allows to compare preoperative versus postoperative state of disease. Short-term mission surgery is a vital part of healthcare delivery to underdeveloped and poor regions. Future missions should aim at sustainable partnerships with local healthcare providers to ensure postoperative care and long-term patient-oriented follow-up. A shift towards a diagonal treatment delivery approach, whereby local surgeons and healthcare staff are educated and empowered, should be actively promoted. PROSPERO registration number CRD42020181931.
Strengths and limitations of this study

- Our statistical approach (qualitative synthesis) allowed us to compare different outcome measurement methods and give a recommendation for use of classification systems.

- Evidence on surgical methods, outcome and followup after Noma disease is scarce and of low quality, which limits the strength of this systematic review.

- The majority of the studies included in this systematic review were case series, which are considered low-quality evidence and therefore limit the generalisability of the results.

- The publications we found represent only a small part of reconstructive surgical missions conducted for Noma disease, which could lead to potential bias of the results.

- Substantial heterogeneity between studies, including differences in outcome measurement and follow-up, limited our ability to draw clear conclusions about how safe reconstructive missions for Noma surgery are.

\section{INTRODUCTION}

Noma is a gangrenous ulcerating bacterial disease of multifactorial origin, mostly prevalent in sub-saharan Africa. Due to the high reported mortality rate of up to $85 \%-90 \%$, and its frequent occurrence in regions of extreme poverty, the WHO officially declared Noma a public health problem in $1994 .^{1}$ The global incidence is reported as 30 000-140 000 new cases per year. ${ }^{12}$ There are currently 210000 Noma survivors worldwide, according to latest estimates. ${ }^{2}$

Most cases of Noma occur between the ages of 2-7 years old. Malnutrition, poor oral hygiene and poverty are known etiological factors leading to nutritionally acquired immune deficiency syndrome. ${ }^{34}$ Children with this syndrome present with lymphatic atrophy and impaired cellular immune responses, as accompanied by increased 
vulnerability to infections. ${ }^{5}$ These preconditions lead to pathogen invasion through the gingival mucosa. ${ }^{67}$ After opportunistic infections take hold, progression to Noma disease occurs in several stages, starting with a simple gingivitis and ending in sequelae such as trismus, feeding difficulties and facial disfigurement. ${ }^{1}$ Surgical reconstructive missions have become an established method to reduce the impact of diseases like Noma. The long-term patient benefit of these missions has come under scrutiny on multiple occasions, most recently by Hendriks $e t \mathrm{al}^{8}$

The purpose of this systematic review is to analyse the currently used classification systems and compare methods of outcome assessment. In addition, the safety and patient-benefit of these procedures are analysed through comparison of complication rates and long-term outcomes.

\section{METHODS}

A comprehensive, structured literature search of published articles was conducted. This was designed by the authors SS and WR and performed in adherence to the Preferred Reporting Items for Systematic Reviews and Meta-analyses (PRISMA). ${ }^{9}$ Methods are described in more detail in the following sections.

\section{Data sources}

The literature search was performed using the electronic databases MEDLINE (PubMed), EMBASE and Web of Science, including articles published between 1 January 1983 and 15 April 2020. The keywords used in the search were selected from key papers and can be found in online supplemental material-part A. Search strings 1 and 2 were combined using the Boolean term AND, then the limits were applied. In addition, a 'MeSH term' search was conducted, and the reference lists of included articles were reviewed for any additional articles.

\section{Study eligibility criteria}

Articles were eligible for inclusion if they provided primary empirical evidence of patient outcomes after Noma surgery. The full inclusion and exclusion criteria are detailed in online supplemental material-part A. Articles were eligible in German and English language. Study selection was independently assessed by two reviewers (SS and MMB).

\section{Data extraction and analysis}

Articles were systematically analysed and data extracted using a structured data collection sheet. This data collection template was pilot tested on two selected articles, before being used to assess all included articles. Data extracted included patient demographics (gender, age, comorbidities), and any outcome measurement tools used.

\section{Methodological quality and assessment of bias}

Included studies were assigned a level of evidence based on the Oxford Centre for Evidence Based Medicine. ${ }^{10}$ In
Addition, studies were rated for methodological quality using the methodological index for non-randomised studies (MINORS) criteria, both tools are explained in detail in online supplemental material-part B.11

\section{Statistical analysis}

Data were analysed using IBM SPSS statistics V.24. Descriptive statistics were performed where possible to allow for narrative synthesis. Weighted population mean outcomes were calculated for outcomes of interest.

Meaningful meta-analysis was not possible due to heterogeneous study design and outcome reporting. Averages were represented as a mean and range for normally distributed data and median with IQR for non-normally disributed data. Outcomes were weighted for size of study population, as some studies had larger population sizes and therefore higher weighting.

\section{Patient and public involvement}

Neither patients nor the public were involved in this research.

\section{RESULTS \\ Selection of studies}

In total, the systematic literature search identified 1393 records. In addition, 7 records were identified through bibliography review. After excluding duplicates, titles and abstracts of 1113 articles were screened, with 1049 being excluded. Sixty-four studies were fully assessed for eligibility according to the criteria previously established. Thirty-three articles were excluded, 23 of which did not report any outcomes of surgery and 6 had duplicate study populations.

Data were extracted from the 31 included articles. Data extraction was pilot tested on two studies and then performed by two independent reviewers (MMB and SS), using a data extraction sheet designed a priori. The selection process was performed according to the PRISMA flow chart, as seen in online supplemental material-part C.

\section{Details of the studies}

In total, data were available for articles published in the period from 1 January 1983 to 15 April 2020. The methodology, diagnostic approach and surgical treatment varied significantly between the studies. In total, published data for 1244 patients from 31 studies were analysed, out of which 1110 patients had reconstructive surgery for Noma disease. In cases of mixed disease populations, estimates were made based on population overall descriptive statistics, dividing the total outcome by Noma population proportions. Patient populations ranged from 2 to 148 patients, with an average of 36 Noma patients enrolled per study. Twenty-nine studies were case series, 4 of them were prospective, ${ }^{12-15} 25$ were retrospective. Two publications had at least two cohorts, ${ }^{16-18}$ two were retrospective 
cohort studies and one was a prospectively designed cohort study. ${ }^{17}$

The overall quality of the studies was low. Three publications ${ }^{16-19}$ were graded with an evidence level III according to the Oxford CEBM. The remaining 28 studies were retrospective case series graded as level IV. The MINORS criteria ${ }^{11}$ were used to rate quality of methods of the included studies. The overall MINORS scores ranged from 1 to 8 points, as seen in online supplemental material-part D. Proportional scores were calculated as a percentage of the maximum score of 8 for case series and 12 for cohort studies. Scores ranged from 13\% to $75 \%$ of the maximum amount of points. The quality level was generally low: more than half of the studies did not even reach $50 \%$ of the ideal outcome.

\section{Patient characteristics}

Median age for operation was 17 years, reported by 23 studies and ranged from 4.5 to 35.7 years. 584 (53\%) female and $424(38 \%)$ male patients were included. For $102(9 \%)$ patients the gender was not known. The median percentage of female population was $56 \%(43 \%-65 \%)$.

Six studies had a malnutrition rate ranging from $25 \%$ to $100 \%$, with an average of over $56 \%$ (median (IQR)) $(53.5(25 \%-81 \%))$ of patients being severely malnourished on study inclusion. No specific details were given on how malnutrition was measured in the included studies. HIV status was stated by six studies, of which five prescreened patients, and only included HIV seronegative patients. ${ }^{160-23}$

\section{Classification systems}

The two most common classification systems were the NOITULP, introduced by Marck et $a l^{15}$ and the Montandon/WHO, first described by Montandon $e t a l^{24}$ as seen in figure 1 .

The NOITULP approach uses the letters N-'nose', O-'outer cheek', I-'inner cheek', T-'trismus', U-'upper lip', L-'lower lip' and P-'particularities' to describe the anatomical subunits affected and gives them a rating from 0 to 4 , depending on the severity of the defect. Nose, cheek, lip and maxilla/mandible involvement were the most commonly mentioned fields, as seen in figure 2.

Six of the included studies used the Montandon classification to rate disease severity. ${ }^{1425-29}$ Type I represents a

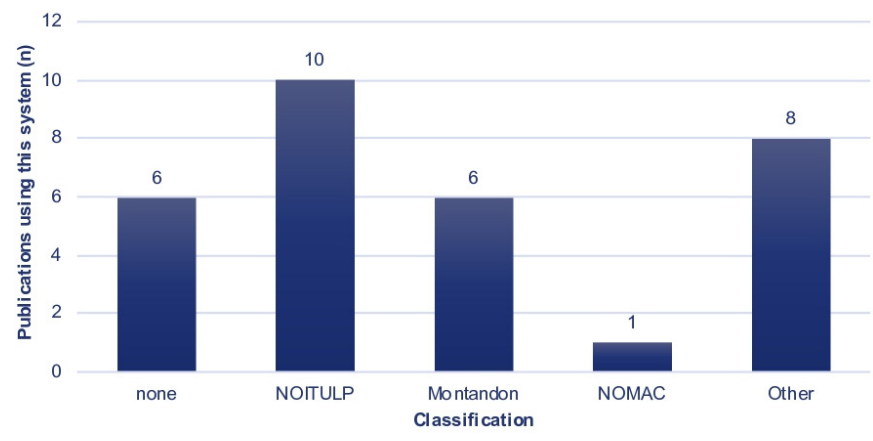

Figure 1 Noma classification systems used 6.

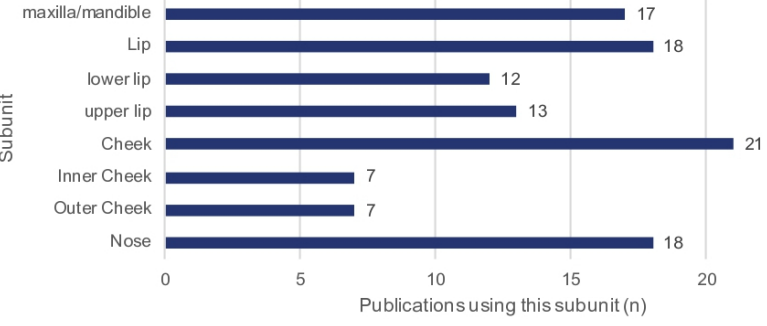

Figure 2 Subunits used for disease classification 6.

localised lip, commissure or cheek defect that normally can be lined by local tissues and covered with a single flap. Type II includes an upper lip and nose amputation. Type III involves a lower lip and mandible amputation, and type IV marks large defects involving the lips, cheek, palate, maxillary bone, orbital floor and other entities.

Montandon classification data were available on 376 patients. Out of these, 147 (39\%) patients were classified as Montandon type I, 53 (14\%) presented as Montadon type II, $15(4 \%)$ were rated as Montandon type III and $161(43 \%)$ patients had Montandon type IV.

Trismus as a complication of Noma disease was stated by 26 studies. On average, 59.6\% (39.2-95.9) of the patient population per study presented with trismus. Trismus was further subdivided into T1-T4 in 257 patients, as seen in figure 3 .

The mean preoperative mouth opening (MO) was calculated only for the 257 patients that further divided the trismus classifications into T1-T4. the population weight corrected mean was used as a proxy for comparison where average values were not provided by the original publication. Population weight-corrected median preoperative $\mathrm{MO}$ was $7 \mathrm{~mm}$ (5-15 mm).

\section{Surgical interventions}

Hospital duration ranged from 2 to 140 days, with a mean of 5.5 days. Two hundred and fifty-five patients were treated by local surgeons in six studies $(23 \%)$ and 855 patients were operated on by mission surgeons in 20 of the studies $(77 \%)$.

\section{Outcomes and follow-up time}

Objective outcomes were further subdivided into two categories, trismus (MO) and complication rate.

\section{Complication rate as outcome}

In total, 204 complications were reported in 24 studies. Median complication rate was $24 \%(13 \%-53 \%)$ per study and ranged between $1 \%$ and $200 \%$. The $200 \%$ complication rate was seen in a study by Hartman $e t a l,{ }^{30}$ where six complications occurred in three patients.

The most common short-term complications can be seen in table 1. Long-term complications over 12 months were only stated in two publications. Bisseling et $a l^{31}$ reported on long-term results of 36 patients undergoing trismus release with mean follow-up of 43 months (12-78). $22 \%$ of these patients experienced difficulties eating and $14 \%$ had difficulties with speaking. Honeyman et $a l^{16}$ 


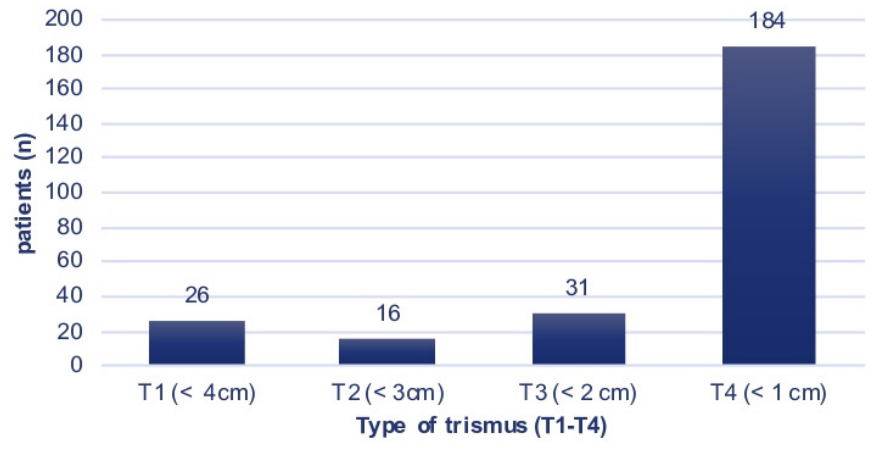

Figure 3 Trismus severity reported preoperatively 6 .

reported 15 long-term complications: chronic fistula $(n=6)$, chronic infection $(n=3)$, chronic pain $(n=2)$, keloid scarring $(n=2)$, wound breakdown $(n=1)$, exposed metal work $(n=1)$. In total, $30 \%$ of the population (21 patients) experienced long-term complications.

\section{Trismus M0 as outcome}

Trismus release, stated as a postoperative $\mathrm{MO}$ of $>3 \mathrm{~cm}$, was achieved in 189 out of 349 patients, reported by 13 publications. Average rate of successful trismus release was 53\%. Three publications reported a $100 \%$ postoperative trismus release rate. ${ }^{23} 2932$ Persisting trismus after surgery was reported in eight publications and was present in 83 out of 286 cases $(29 \%)$.

Mean postoperative MO was reported only by eight publications and ranged from 23 to $35 \mathrm{~mm}$. Populationweighted mean postoperative $\mathrm{MO}$ was $27 \mathrm{~mm} .{ }^{24-27}$

Mean MO at long-term follow-up was available for five publications and ranged from 10.3 to $35.0 \mathrm{~mm}$. Population-weighted mean MO at long-term follow-up was $20 \mathrm{~mm}$ (median (IQR)) (19 (15-21). Figure 4 shows population-weighted mean MO preoperatively, postoperatively and at long-term follow-up.

\section{Subjective outcome measures}

Subjective postoperative outcomes included cosmetic/ aesthetic improvement, reported by three studies, and overall improvement (aesthetic and functional), reported by eight publications. No further details on how improvement was measured was given by the publishers. No information on if this was patient-measured or observermeasured was stated.

\begin{tabular}{ll}
\hline Table 1 & Most common short-term complications \\
\hline Complication & Rate $\mathbf{n}(\%)$ \\
\hline Infection & $37(18)$ \\
\hline Partial flap necrosis & $26(13)$ \\
\hline Total flap loss and necrosis & $20(10)$ \\
\hline Bleeding/haematoma & $12(6)$ \\
\hline Donor site dehiscence & $12(6)$ \\
Recurrent fistula & $11(5)$ \\
\hline Others & $20(10)$ \\
\hline
\end{tabular}

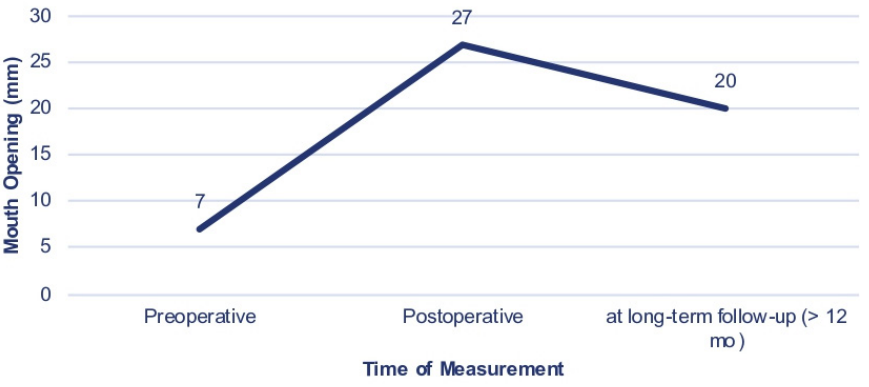

Figure 4 Mouth opening at preoperative, postoperative and long-term follow-up points 7.

Median length of follow-up was reported by only eight publications, which was 24 months (12.7-45) and ranged from 31 days to 324 months (27 years). ${ }^{28}$ Death was reported in 23 cases $(2 \%) .{ }^{25} 33$ Nath and Jovic reported on 81 patients treated on Noma which were HIV positive in Zambia, out of which 11 patients died during initial medical treatment for infection, and 12 (13.6\%) died following minor surgery. No further information on comorbidities or health status of these children was provided. In the study published by Chidzonga and Mahomva, all patients were HIV seropositive. One patient developed severe pneumonia and died before reconstructive surgery, another patient died 1 month after admission, no further detail on the cause of death was given. One-third patient died 1 month after initial soft tissue debridement and sequestrectomy. All patients showed severe facial tissue loss and dentoalveolar necrosis.

Long-term follow-up, which was defined as longer than 12 months, was reported by only six publications (263 patients in total), and mean loss to follow-up was $56 \%$.

\section{DISCUSSION}

Noma affects mostly children in the poorest and least developed regions of the world. It causes facial disfigurement and can lead to functional impariment such as loss of oral competency including salivary leakage and trismus. This is the first systematic review specifically analysing the classification, complications and long-term outcomes of Noma surgery, both in local and in mission surgery settings.

Thirty-one studies met the inclusion criteria, with a total of 1110 patients included which had undergone reconstructive surgery for Noma disease. The overall methodological quality of the studies, rated by the MINORS criteria, was poor and reflects similar outcomes of the systematic review on trismus conducted by Bouman et al. ${ }^{34}$ Over half the studies we included reached $50 \%$ or less in the MINORS score. Non-randomised studies with high quality are usually rated $83 \%$ and higher, according to Slim $e t a l .{ }^{11}$ Out of the 31 studies included, four of them were prospective, and two of them cohort studies.

The methodological limitations of this study include the low-quality evidence of articles and heterogeneity between studies. This led to the lack of data stratification 
towards parameters such as age, first surgery versus revision surgery and type of defect.

Challenges of performing rigorous studies in the developing world include limited resources and the short time frame of 2-3 weeks, which the surgeons typically spend on surgical missions. This can be improved by promoting a system where high-quality research can be provided by local staff with the support of plastic surgeons from more developed countries, advocating an academically profitable partnership, sustainable throughout the year.

Classification systems have been proposed by several authors, the two most commonly used were NOITULP, introduced by Marck et $a l^{15}$ and Montandon/WHO, first described by Montandon $e t a l^{24}$

Montandon et $a l^{24}$ based their system on two publications by Raynaud $e t a l^{35}$ and Cariou. ${ }^{36}$ The approach Montandon suggested was rating the defect based on its severity, taking into account the surgical strategy needed to successfully reconstruct the face.

Marck et al found that the previously described classifications lacked in brevity as in conciseness and were not quantifiable in the way NOITULP is. ${ }^{15}$ NOITULP covers anatomical subunits and severity of defect, not previously taken into account by any system.

While the Montandon classification has been validated by the WHO in 1994, ${ }^{1}$ Noma surgeons are still using both classification systems in parallel. While the Montandon classification is simple and easy to comprehend and apply, it might not fully grasp the disease severity, and it misses one important disease characteristic: trismus. However, the NOITULP classification has a more holistic approach and is more complex in its entirety. The question to be asked is, what do the surgeons want to achieve by using the tool and how can we compare the preoperative to postoperative state of the patients and ideally use it as a control system for disease relapse or progression in trismus patients. In addition, the system must be comprehensible by the surgeon using it, which ultimately shall be a surgeon within the local healthcare system. One suggestion might be to distinguish between a role for a more complex classification to be used predominantly in the research setting, while the other could have a more direct clinical role. In addition, the role of patient-reported outcome measures (PROMs) should be explored with Noma patients for preoperative and postoperative evaluation. If the patient does feel that they have benefited from the operation, this may be more relevant than the surgeons' report or the classification system. Validated questionnaires are one possible way to report patientreported outcomes. ${ }^{37}$ They are essential for preoperative and postoperative interviews and evaluation of the patients view on benefit from the operation.

Out of the 31 studies analysed, in only six studies were the operations undertaken by a local surgeon. The majority of operations were undertaken by mission surgeons travelling to the region. This vertical approach to healthcare includes short missions of 2-3 weeks. Unfortunately, these missions are typically characterised by a higher risk of poor follow-up. They are also often fail to provide a holistic approach to the patient's ongoing treatment after surgery, especially when compared against clinics that include permanent local surgeons and healthcare staff. ${ }^{8}$ This was well reflected in the outcomes and follow-up seen in the 31 publications we analysed. Outcome measurements were inconsistent, and follow-up was incomplete in the majority of publications $(81 \%)$.

While postoperative complication rates were available for the majority of studies (77\%), long-term complications were only reported by two publications. Bisseling et $a l^{31}$ reported that $22 \%$ of patients experienced loss of oral competency and $14 \%$ had difficulties with speaking. Honeyman et al reported a $30 \%$ long-term complication rate. These high long-term complication rates, including severe complications such as loss of oral competency, make the long-term benefit of these short-term missions questionable, as stated previously by Hendriks et al. ${ }^{8}$ Reasons for the high complication rates could be lack of postoperative physiotherapy and/or regular follow-up visits. It is therefore important that any surgical missions develop links with the local healthcare system in order to ensure that complications can be managed effectively and to provide training where required for local healthcare workers.

Postoperative $\mathrm{MO}$ as an outcome of trismus release was reported by eight studies, and long-term follow-up data were available for five publications. Under-reporting of outcomes and limited follow-up under-reporting of outcomes and lack of follow-up could lead to underestimation or overestimation of benefits to the patients. Nevertheless, population-corrected mean postoperative MO at long-term follow-up (>12 months) was $20 \mathrm{~mm}$, which represents a $13 \mathrm{~mm}$ increase compared with the preoperative mean. It is worth mentioning at this point, that there is broad range of ages for the patients included in this review. Whether a $20 \mathrm{~mm}$ increase in $\mathrm{MO}$ is of any relevance changes based on age as an adult mouth is larger than a young child's mouth. Unfortunately, no further details were given on the ages of the patients measured at long-term follow-up. Also, most cases of Noma occur between the ages of 2 and 7 years old, and the median age of the reconstruction was 17 years (range from 4.5 to 35.7 ), so the long-term evolution may influence the outcome.

Bisseling $e t a l^{31}$ followed up patients treated in the Noma Childrens Hospital in Sokoto, Nigeria. In this mission hospital, in the majority of patients, contact is lost entirely after discharge and long-term outcome is not known. Therefore, they tried to revisit the patients in their home communities to retrieve patient outcome data. Out of 130 patients documented, only 36 patients were found and included into the study, representing a greater than $70 \%$ loss to follow-up rate. Similarly high losses were reported by Pittet et al (79\%) and Vinzenz et $a .^{38}(78 \%)$ and slightly less by Dammer et al $(50 \%)$, reflecting the challenges of providing adequate ongoing care in the developing world. Reasons for high lost to 
follow-up could be inconsistency in local healthcare provision and lack of infrastructure and long distances that have to be overcome by the parents and the child to reach the local clinics.

Rüegg et $a l^{27}$ lost only $21 \%$ of their patients to follow-up, with their patients being treated in Switzerland and repatriated following discharge from hospital. They were followed up by the local healthcare workers of the Swiss charity Sentinelles. They implemented a local complication report and follow-up system, working together with physiotherapists and ensuring local healthcare support and regular controls throughout the year. Whereas it is often not feasible to fly Noma patients to Europe for treatment, their strategy of consistent local care and staff to oversee the postoperative healing process on site helped them stay connected with their patients and ensured their well-being after reintegration.

Transition from a vertical approach, where short-term missions are performed, but no activities throughout the year are supported, to a more diagonal strategy, used for mission surgery in underdeveloped countries, has previously been suggested by Patel $e t a .^{39}$ In this model, which was originally developed for cleft lip and palate patients, they combine short-term missions with ongoing measures such as the support of local staff with residency programmes, financial support, research training, academic partnerships and equipment for surgery.

This sustainable treatment strategy was further promoted by Hendriks $e t \mathrm{al}^{8}{ }^{8}$ Working together with local staff and implementing a mutually beneficial partnership helps ensure a holistic approach towards healthcare provision and management in underdeveloped countries.

Advantages of this system include development of a long-term presence in the respective countries with the ultimate goal of building local surgical capacity and treatment independence in a supported setting. Visiting surgeons benefit from experience in global healthcare delivery and have the chance to transfer their knowledge to local surgeons, who gain surgical skills and experience. In addition, other local healthcare workers can be trained including nutritionists, physiotherapists and speech therapists, to support the patients in the perioperative settings. ${ }^{39}$

Data on how far this has been implemented in hospitals treating Noma patients is scarce. However, given the low long-term follow-up rate and incomplete reporting of outcomes in studies published up to date, implementation of this model is likely limited in Noma patients.

The diagonal treatment strategy combined with a patient-centred outcome evaluation system including PROMs in the form of validated and standardised questionnaires could lead to a sustainable, patient-centred and holistic treatment system for survivors of Noma disease.

The systematic review conducted demonstrates the current most common classification systems used, outcomes and follow-up for reconstructive surgery following Noma disease to date. Consistency in classifying and following up on patients imposes a challenge for neglected diseases in developing countries, no less so for Noma. When classifying disease severity of Noma patients, surgeons should aim to achieve comparability of the preoperative versus postoperative and long-term status by using a classification system that allows documentation of affected anatomical subunits, as well as to note trismus severity at every point in follow-up.

Tools for measuring surgical outcomes in Noma patients are scarce and need further research and validation. Complication rates and $\mathrm{MO}$ were the two most commonly reported outcomes. In general, reported outcomes were often inconsistent and of low quality, as was evidence of follow-up data. Short-term mission surgery is a vital part of healthcare delivery to underdeveloped regions. Future missions should focus on fostering cooperation and forming partnerships with local organisations to ensure postoperative care and long-term patient-oriented follow-up. A shift towards a diagonal treatment delivery approach where local surgeons and healthcare staff are educated and supported should be actively promoted.

Contributors SS: first reviewer, design of study, data analysis, data interpretation, manuscript preparation. MMB: second reviewer, design of study, data interpretation, manuscript preparation. BL: third reviewer, design of study, data interpretation, manu-script preparation Mr HK, M.D.: design of study, manuscript preparation. WR: design of study, data interpretation, manuscript preparation.

Funding The article processing charge was kindly paid for by University College London as part of their Open Access policy.

Competing interests None declared.

Patient consent for publication Not required.

Provenance and peer review Not commissioned; externally peer reviewed.

Data availability statement № additional data available.

Supplemental material This content has been supplied by the author(s). It has not been vetted by BMJ Publishing Group Limited (BMJ) and may not have been peer-reviewed. Any opinions or recommendations discussed are solely those of the author(s) and are not endorsed by BMJ. BMJ disclaims all liability and responsibility arising from any reliance placed on the content. Where the content includes any translated material, BMJ does not warrant the accuracy and reliability of the translations (including but not limited to local regulations, clinical guidelines, terminology, drug names and drug dosages), and is not responsible for any error and/or omissions arising from translation and adaptation or otherwise.

Open access This is an open access article distributed in accordance with the Creative Commons Attribution Non Commercial (CC BY-NC 4.0) license, which permits others to distribute, remix, adapt, build upon this work non-commercially, and license their derivative works on different terms, provided the original work is properly cited, appropriate credit is given, any changes made indicated, and the use is non-commercial. See: http://creativecommons.org/licenses/by-nc/4.0/.

\section{ORCID iD}

Sophie Speiser http://orcid.org/0000-0001-7099-4395

\section{REFERENCES}

1 Bourgeois DM, Leclercq MH. The world Health organization initiative on noma. Oral Dis 1999;5:172-4.

2 Srour ML, Marck K, Baratti-Mayer D. Noma: overview of a neglected disease and human rights violation. Am J Trop Med Hyg 2017;96:268-74.

3 Chandra RK. 1990 McCollum Award Lecture. nutrition and immunity: lessons from the past and new insights into the future. Am J Clin Nutr 1991;53:1087-101.

4 Leila Srour M, Marck KW, Baratti-Mayer D. Noma: neglected, forgotten and a human rights issue. Int Health 2015;7:149-50. 
5 Beisel WR. Nutrition and immune function: overview. J Nutr 1996;126:2611S-5.

6 Baratti-Mayer D, Gayet-Ageron A, Hugonnet S, et al. Risk factors for noma disease: a 6-year, prospective, matched case-control study in niger. Lancet Glob Health 2013;1:e87-96.

7 Baratti-Mayer D, Pittet B, Montandon D, et al. Noma: an "infectious" disease of unknown aetiology. Lancet Infect Dis 2003;3:419-31.

8 Hendriks TCC, Botman M, Rahmee CNS, et al. Impact of short-term reconstructive surgical missions: a systematic review. BMJ Glob Health 2019;4:e001176.

9 Moher D, Shamseer L, Clarke M, et al. Preferred reporting items for systematic review and meta-analysis protocols (PRISMA-P) 2015 statement. Syst Rev 2015;4:1.

10 Burns PB, Rohrich RJ, Chung KC. The levels of evidence and their role in evidence-based medicine. Plast Reconstr Surg 2011;128:305-10.

11 Slim K, Nini E, Forestier D, et al. Methodological index for nonrandomized studies (minors): development and validation of a new instrument. ANZ J Surg 2003;73:712-6.

12 Bouman MA, Marck KW, Griep JEM, et al. Early outcome of noma surgery. J Plast Reconstr Aesthet Surg 2010;63:2052-6.

13 Dammer R, Dünzl B, Kühnel T. [Therapy of bony and fibrous contractures and buccal defects after noma using the temporalis muscle flap]. Mund Kiefer Gesichtschir 2005;9:225-32.

14 Kühnel TS, Dammer R, Dünzl B, et al. New split scar cheek flap in reconstruction of noma sequelae. Br J Plast Surg 2003;56:528-33.

15 Marck KW, de Bruijn HP, Schmid F, et al. Noma: the Sokoto approach. Eur J Plast Surg 1998;21:277-80.

16 Honeyman C, Patel V, Yonis E, et al. Long-term outcomes associated with short-term surgical missions treating complex head and neck disfigurement in Ethiopia: a retrospective cohort study. J Plast Reconstr Aesthet Surg 2020;73:951-8.

17 Huijing MA, Marck KW, Combes J, et al. Facial reconstruction in the developing world: a complicated matter. Br J Oral Maxillofac Surg 2011;49:292-6.

18 Marck R, Huijing M, Vest D, et al. Early outcome of facial reconstructive surgery abroad: a comparative study. Eur J Plast Surg 2010;33:193-7.

19 Oluwasanmi JO, Lagundoye SB, Akinyemi OO. Ankylosis of the mandible from cancrum oris. Plast Reconstr Surg 1976;57:342-50.

20 Giessler GA, Borsche A, Lim PK, et al. First experiences with simultaneous skeletal and soft tissue reconstruction of noma-related facial defects. J Reconstr Microsurg 2012;28:085-94.

21 Giessler GA, Cornelius CP, Suominen S, et al. Primary and secondary procedures in functional and aesthetic reconstruction of nomaassociated complex central facial defects. Plast Reconstr Surg 2007;120:134-43.

22 Giessler GA, Fieger A, Cornelius C-P, et al. Microsurgical reconstruction of noma-related facial defects with folded free flaps: an overview of 31 cases. Ann Plast Surg 2005;55:132-8.
23 Giessler GA, Schmidt AB. Noma: experiences with a microvascular approach under West African conditions. Plast Reconstr Surg 2003;112:947-54.

24 Montandon D, Lehmann C, Chami N. The surgical treatment of noma. Plast Reconstr Surg 1991;87:76-86.

25 Chidzonga MM, Mahomva L. Noma (cancrum oris) in human immunodeficiency virus infection and acquired immunodeficiency syndrome (HIV and AIDS): clinical experience in Zimbabwe. J Oral Maxillofac Surg 2008;66:475-85.

26 Pittet B, Jaquinet A, Montandon D. Clinical experience in the treatment of noma sequelae. J Craniofac Surg 2001;12:273-83.

27 Rüegg EM, Baratti-Mayer D, Jaquinet $A$, et al. The surgical management of extra-articular ankylosis in noma patients. Int $\mathrm{J}$ Oral Maxillofac Surg 2018;47:1527-33.

28 Rüegg EM, Gniadek P, Modarressi A, et al. Facial bone reconstruction with prefabricated vascularized calvarium flaps in children and young adults: advantages and long-term results. $J$ Craniomaxillofac Surg 2016;44:1880-8.

29 Simon F, Wolfe SA, Guichard B, et al. Paul Tessier facial reconstruction in 1970 Iran, a series of post-noma defects. J Craniomaxillofac Surg 2015;43:503-9.

30 Hartman EHM, Van Damme PA, Sauter $\mathrm{H}$, et al. The use of the pedicled supraclavicular flap in noma reconstructive surgery. J Plast Reconstr Aesthet Surg 2006;59:337-42.

31 Bisseling P, Bruhn J, Erdsach T, et al. Long-term results of trismus release in noma patients. Int J Oral Maxillofac Surg 2010;39:873-7.

32 Holle J. Lockjaw treatment after noma in the third World. J Craniofac Surg 2009;20 Suppl 2:1910-2.

33 Nath S, Jovic G. Cancrum oris: management, incidence, and implications of human immunodeficiency virus in Zambia. Plast Reconstr Surg 1998;102:350-7.

34 Bouman MA, Dijkstra PU, Reintsema H, et al. Surgery for extraarticular trismus: a systematic review. Br J Oral Maxillofac Surg 2016;54:253-9.

35 Reynaud J, Garand G, Ployet MJ. Du noma Au syndrome de Silvermann: une pathogĖnie $\ddagger$ discuter. Ann Chir Plast 1978;23:227-30.

36 Cariou J. Le noma dans La corne de I'Afrique: approche thérapeutique. Ann Chir Plast Esthet 1986.

37 Weldring T, Smith SMS. Patient-Reported outcomes (pros) and patient-reported outcome measures (PROMs). Health Serv Insights 2013;6:61-8.

38 Vinzenz K, Holle J, Würinger E. Reconstruction of the maxilla with prefabricated scapular flaps in noma patients. Plast Reconstr Surg 2008;121:1964-73.

39 Patel PB, Hoyler M, Maine R, et al. An opportunity for diagonal development in global surgery: cleft lip and palate care in resourcelimited settings. Plast Surg Int 2012;2012:892437 